\title{
Sob o tremor das imagens: política e ação direta na lente xavante
}

\author{
Dolores Galindo' \\ https://orcid.org/0000-0003-2071-3967 \\ Gilson Costal \\ https://orcid.org/0000-0002-3318-629X
}

I - UFMT

Cuiabá (MT), Brasil

Resumo: Este artigo dimensiona o uso da produção audiovisual indígena como recurso estratégico na luta por direitos. Interessa-nos dar relevo para a presença determinante da câmera enquanto dispositivo que oscila como arma política, colocando-se no centro do conflito como testemunha ocular. Nossa análise baseia-se em dois documentários realizados pelo cineasta xavante Divino Tserewahú. O primeiro é o registro do confronto direto ocorrido entre indígenas da comunidade de Sangradouro e autoridades policiais do município de Primavera do Leste (MT), impulsionado após a detenção de um jovem da comunidade. O segundo é um documentário sobre as comemorações dos 25 anos da política do Povo Macuxi pela homologação da Terra Indígena Raposa Serra do Sol, em Roraima.

Palavras-chave: audiovisual; povo Xavante; cinema indígena.

Abstract: Under the tremor of images: politics and direct action on the Xavante lens - This paper seeks to measure the use of indigenous audiovisual production as a strategic resource in the struggle for rights. We are interested in highlighting the determining presence of the camera as a recording device that oscillates as a political weapon, placing itself at the center of the conflict as an eyewitness. For this our analysis is based on two documentaries made by Xavante Divino Tserewahú. The first is the record of the direct confrontation between indigenous people of the Sangradouro community and police authorities of the municipality of Primavera do Leste, driven after the allegedly illegal arrest of a young man from the community. The second is a documentary about the 25th anniversary celebration of the Macuxi People's struggle for the homologation of the Raposa Serra do Sol Indigenous Land, in Roraima.

Keywords: audiovisual; Xavante people; indigenous cinema. 


\section{Introdução}

Notadamente, a virada da década de 1990 significou um marco importante para a atuação de militantes indígenas no audiovisual. A expertise política, acumulada desde a articulação do movimento indígena, em meados dos anos de 1970, bem como a participação exitosa no processo Constituinte de 1988, proporcionaram projeção internacional para diferentes etnias. Note-se que a atuação política indígena resultou em conquistas históricas no texto constitucional, a exemplo do Artigo 231, que versa sobre o direito originário à posse dos territórios tradicionais. No âmbito interno, a ação de indigenistas e apoiadores inaugurava a relação promissora que diferentes povos passariam a ter com a apropriação sistemática de instrumentos de produção audiovisual para fins culturais e políticos.

Essa ascensão, conforme admitido por Clarisse Alvarenga (2004), não pode ser dissociada de uma atmosfera mais ampla, constituída, em grande medida, em campo de ação política que envolveu diferentes atores sociais, os quais empreenderam esforços para a conquista de uma sociedade democrática. Emergia uma conjuntura em que movimentos sociais, sindicatos e setores populares vislumbravam na tecnologia do vídeo uma importante componente para enfrentar os desafios políticos que se originavam do Estado militarizado, autoritário e perseguidor de direitos sociais.

Para os povos indígenas, a apropriação dos meios de comunicação, sobretudo os de produção audiovisual, atua como canal expressivo para a preservação da memória coletiva, autodeterminação e afirmação cultural. Neste artigo, baseado em pesquisa realizada em acervos audiovisuais e com os indígenas Xavante da comunidade de Sangradouro, em Mato Grosso, interessa-nos dar relevo à presença determinante da câmera enquanto dispositivo de registro que oscila como arma política (para dar visibilidade pública aos fatos filmados) e sentinela (no sentido de colocar-se no centro do conflito como testemunha ocular).

É expressivo constatar que os filmes sobre as práticas cerimoniais do povo Xavante, realizados pelo cineasta Divino Tserewahú ${ }^{1}$, são obras que possuem reconhecimento internacional e, reiteradamente, participam de importantes mostras e festivais. Todavia, existe uma escala de produção anônima, articulada estrategicamente como atos de defesa e de garantias de direito, que merece, igualmente, atenção. Nossa análise, para além de uma mirada sobre os procedimentos técnicos da montagem e dos elementos inscritos na composição e fotografia do quadro fílmico, volta-se ao audiovisual indígena como prática política articulada à defesa de direitos. Interessa-nos o gesto de filmar e as narrativas audiovisuais indígenas como armas e testemunhas de processos políticos.

Argumentamos que a materialidade da câmera e a presença do cineasta produzem ruptura no transcorrer dos fatos, desencadeando a ocorrência daquilo que Ismail Xavier (2014) denomina de "efeito-câmera". Nesses filmes, é possível observar como o campo

1 Formado pelo projeto Vídeo nas Aldeias, Divino Tserewahú é cineasta da etnia Xavante, morador da Terra Indígena Sangradouro, no estado de Mato Grosso, e possui vasta filmografia alusiva a aspectos culturais de seu Povo. 
é invadido pelo antecampo ${ }^{2}$ rompendo, radicalmente, a distância entre quem filma e quem está sendo filmado.

Com o intuito posto, discutiremos dois produtos audiovisuais originados de situações em que houve a participação efetiva do cineasta e de sua câmera ao registrar ocorrências de embates políticos permeados por alto nível de tensão. Mais especificamente, analisamos duas peças: a primeira é o registro do confronto direto entre indígenas Xavante da comunidade de Sangradouro e autoridades policiais do município de Primavera do Leste (MT), impulsionado pela detenção, supostamente ilegal, de um jovem da comunidade; a segunda obra é um documentário sobre as comemorações dos 25 anos da luta do povo Macuxi pela homologação da Terra Indígena (TI) Raposa Serra do Sol, em Roraima. Estes dois casos, além de suas respectivas singularidades, denotam como a presença do sujeitoda-câmera (RAMOS, 2012) se converte em componente indissociável dos confrontos registrados, interferindo no próprio rumo dos acontecimentos postos sob o olhar da lente.

\section{Quem não pode com a formiga não assanha o formigueiro}

O episódio que passamos a narrar está situado temporalmente no segundo semestre do ano de 2008, mais precisamente nos meses de outubro e novembro. Ocorreu na cidade de Primavera do Leste (MT), município localizado a cerca de $40 \mathrm{~km}$ da Terra Indígena Sangradouro. Após a prisão de um rapaz xavante, a revolta da comunidade desencadeou uma sucessão de atos que perderam o controle e resultaram na retenção temporária, pelos Xavante, de um delegado da Polícia Civil e sua consequente "troca" pelo indígena que fora detido. Em meio à indignação do grupo, houve a ocupação da delegacia, o enfrentamento direto com a Polícia Militar e ameaças com arma de fogo de ambos os lados. Imbricados no confronto, o cineasta e sua câmera firmaram-se como sentinelas e testemunhos da atuação destemida daquele coletivo. O registro da ação e a presença da câmera foram uma estratégia utilizada pela comunidade desde o momento em que esta optou por realizar a empreitada. Nesse contexto, a câmera era mais uma arma que se somava às bordunas ${ }^{3}$, pedras e carabinas empunhadas pelos aguerridos personagens.

Constatamos que os Xavante de Sangradouro apresentam inúmeras reservas quando perguntados sobre o assunto. Não obstante, de acordo com algumas versões que conseguimos apurar com testemunhas, o motivo que desencadeou a prisão do xavante J.C.T. ${ }^{4}$ foi que este teria impedido que sua irmã - uma criança de aproximadamente dez

2 Utilizamos a noção apresentada por André Brasil (2013) e recuperada por Moacir Barros (2014). Para este último, o antecampo é o "espaço atrás da câmera, no qual permanecem, tradicionalmente, o cineasta e a equipe de filmagem, fora do mundo da representação diante da câmera, em posição de recuo e ocultamento" (BARROS, 2014, p. 21-22).

3 É um instrumento de madeira, em formato de taco, fabricado com troncos de árvores do Cerrado. Tradicionalmente faz parte da tecnologia bélica do povo Xavante.

4 Como trata-se de uma situação permeada de controvérsias, optou-se por manter preservada a identidade desta pessoa e referir-se a ela pelas iniciais de seu nome. 
anos - fosse levada por um casal de não indígenas para o estado de São Paulo. Ao que consta, este casal teria recebido uma espécie de "guarda" autorizada pelo pai de J.C.T. e levaria a criança para a "cidade grande". Como era contrário ao apadrinhamento, o jovem raptou a menina. O casal, por sua vez, fez a denúncia para a polícia, com o objetivo de reaver a criança. Por orientação dos anciões, J.C.T. foi até o município de Primavera do Leste para prestar depoimento e esclarecer a situação. Chegando lá, foi surpreendido com uma ordem de prisão. Ao saber do ocorrido, a comunidade sentiu-se traída, desencadeando uma revolta generalizada. Pessoas de diferentes idades armaram-se com pedras e bordunas. Resolveram, por conta própria, resgatar o cativo:

Quando ele foi preso, os Xavante falaram: podemos buscar ele em Primavera, mas se os policiais não deixarem a gente entrar, não tirarem ele, nós vamos invadir. O câmera [cinegrafista] tem que ir... Tem que filmar. Os Xavante se pintaram, pegaram flecha, borduna e me pediram para levar a câmera. (TSEREWAHÚ, 2018. Comunicação pessoal aos pesquisadores)

O relato de Divino mostra o grau de equivalência dos diferentes dispositivos bélicos. A flecha, a borduna e a câmera foram colocadas, pelo grupo, em um mesmo grau de importância diante da batalha que se anunciava em um curto devir, modulando-se como recursos legítimos para a eficácia da ação pretendida.

O vídeo, intitulado por Tserewahú como Prisão e libertação do jovem xavante (2009), é resultado dos registros realizados durante os enfrentamentos com as forças do Estado $^{5}$ somados às entrevistas de personagens que participaram diretamente da ação. Sua montagem denota o contexto de apreensão em que fora concebido: os enquadramentos são trêmulos; as imagens estão desfocadas e, muitas vezes, com excesso de luz; os ruídos sonoros se misturam aos gritos e traquejos dos personagens; o campo imagético é revolto, enquanto o antecampo é tomado pela tensão. Obviamente, as imagens e sua própria composição dialogam, estética e tecnicamente, com a inquietude do ocorrido.

Esse resultado atesta a presença física do cineasta no espaço mesmo onde se dá a tensão. Seu testemunho se faz com a lente da câmera, mas também com a presença física do seu corpo disputando, com as possibilidades do perigo, o espaço clandestino do registro. Em diferentes segmentos do filme, é possível inferir que a voz de quem filma se mistura aos bramidos externos, acentuando a tênue fronteira entre o cineasta e os aderentes da empreitada. Ao comentar sobre imagens captadas em cenários de iminente litígio, Ramos sugere que tais situações retratam "o tipo de imagem que lança o espectador para a consciência da inserção do sujeito-da-câmera na circunstância que veio deixar seu traço no suporte" (Ibidem, p. 78).

Dada as condições materiais de produção daquelas tomadas, seu principal objetivo era servir como salvaguarda para denunciar possíveis abusos das autoridades e garantir,

5 Em um primeiro momento com as polícias Civil e Militar e, conforme o transcorrer dos fatos, com a Polícia Rodoviária Federal. 
em momento futuro, qualquer espécie de prova material em favor da comunidade. Ocorre que, posteriormente, elas foram editadas, acrescidas a um conjunto de relatos e acabaram se configurando em um videorregistro importante para a comunidade, inclusive, para pensar em sua autocrítica (já que, como fica patente nas imagens, os nervos exaltados provocaram ações excessivas de ambas as partes).

Durante a montagem, as imagens de um grupo de Xavante quebrando as vidraças da delegacia são encadeadas à ação de um outro conjunto de personagens que investem contra uma viatura policial, deixando-a de rodas para o ar (Figura 1). Alguns takes curtos flagram um ou outro manifestante portando arma de fogo. Mesmo diante das consequências negativas que estes registros poderiam trazer para Sangradouro, Divino assume o risco ao entender, junto com os anciões da comunidade, que a ação, além de legítima, ecoa conexões com o espírito guerreiro que historicamente fora atribuído à etnia.

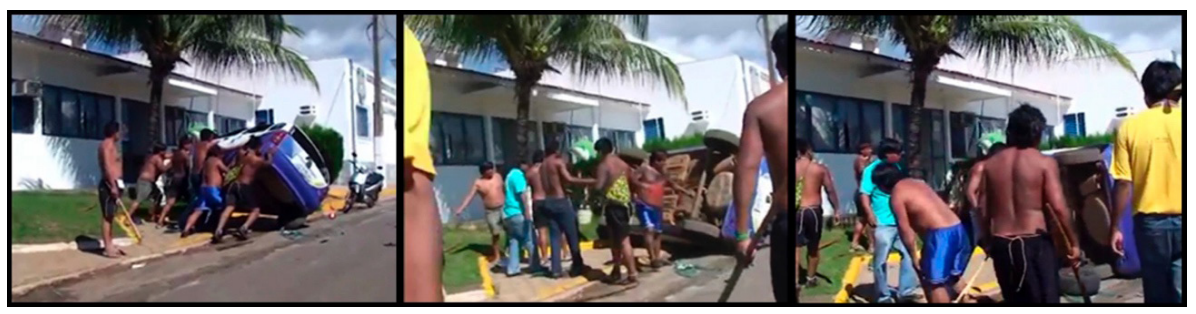

Fig. 1. Grupo Xavante em ação na delegacia de Primavera do Leste - MT. Fonte: Frames do filme Prisão e libertação de jovem xavante (2009).

De outra parte, são encadeadas imagens do delegado retido pelos Xavante no momento da ocupação da delegacia. Fica perceptível que os primeiros contatos do grupo com a autoridade policial são tensos. Neste caso, uma sequência, em particular, merece destaque: desde o momento em que o delegado é abordado, ele tenta se eximir da responsabilidade pela detenção e explicar que o mandado de prisão de J.C.T. fora expedido por outra pessoa. Inclusive, sugere que a sentença era irregular e que estaria ali para tentar resolver a situação. Ele é então levado por outro grupo de manifestantes até o local onde o jovem estaria preso. O fato de o jovem xavante não ser localizado aumenta ainda mais a escala de nervosismo. Na sequência, o grupo conduz o delegado até um veículo e o deixa recluso antes de ser transportado para a aldeia. Neste momento, torna-se possível ouvir sons de sirenes embaralhados aos gritos e evocações em xavante. As lamúrias do agente civil são abafadas em meio aos diferentes ruídos. A mise-en-scène se converte em imagens trêmulas e confusas. Em outra sequência, o delegado aparece na aldeia sentado em um banco no interior de uma residência. Aparenta estar bem, apesar de leve ferimento no braço esquerdo e das roupas manchadas pelo preto e vermelho, respectivamente, do jenipapo e do carvão moído (o que atesta o contato físico com os corpos xavante). 
Em meio à tensão, surge um personagem que passa a fazer parte da negociação entre o grupo xavante e os policiais federais, que a esta altura já estavam à frente do caso. Trata-se de um missionário conhecido como Pe. Luiz, um dos dirigentes da Missão Salesiana, localizada ao lado da aldeia Sangradouro. O fato de este último dominar fluentemente tanto a língua xavante quanto o português parece ser um critério importante no papel que passa a ocupar. Com a eminente presença da câmera, a negociação é conduzida pelos anciões com a intermediação do religioso. A tensão não desaparece, mas agora compõe o background no contexto da cena que prioriza os detalhes do acordo para materializar a barganha do delegado por J.C.T.

Em um dos momentos mais tensos da ação, no qual se efetivou o câmbio dos dois personagens (ou seja: a troca do delegado por J.C.T.), ocorrido no pátio de um posto de combustível na altura do km 250 da BR-070, além dos mediadores presentes (um delegado da Polícia Federal, uma liderança xavante e o missionário), a câmera e seu cinegrafista se somavam à comitiva que operava a intermediação da imponderável permuta (Figura 2). Nesta cena, é notória a expressão utilizada por um dos indígenas presentes: "já podemos fazer a troca! Divino já está filmando".

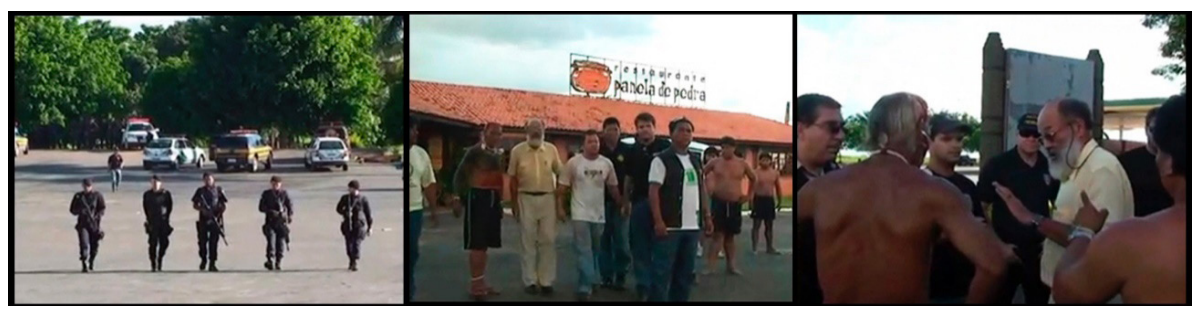

Fig. 2. Negociação entre o grupo Xavante e a Polícia Federal. Fonte: Frames do filme Prisão e libertação de jovem xavante (2009).

À câmera foi dada a função de testemunhar e garantir que o acordo ocorresse conforme o combinado. A ela, enquanto dispositivo ocular, foi atribuída a função de dar garantias à comunidade, no sentido de ter a convicção de que, sob o seu olhar, pairasse alguma espécie de salvo-conduto. No centro desse pleito estavam a câmera e aquele que a empunhava. Para o alívio de ambas as partes, a troca foi feita e os dois personagens entregues, sãos e salvos, para cada um de seus grupos. Neste contexto é possível admitir que, não fosse o olhar atento da câmera (no registro das ações policiais ou no acompanhamento das negociações), o desfecho dessa história poderia não ter tido o mesmo happy end.

No calor do acontecimento, o documentarista e sua câmera conformam a instância criadora da imagem e modulam um campo de intencionalidades que são próprias do sujeito que filma. Para Ramos, "o sujeito expõe a marca de sua intencionalidade sempre ligando com um dado anterior [...]" (2012, p. 17). Em se tratando do realizador 
indígena que, presente na circunstância da tomada, materializou as cenas, seu intento está ancorado nos propósitos de seu povo. Aliás, no caso que estamos analisando, a própria presença do cineasta na geografia da cena é consequência de uma demanda coletiva. O cineasta, assim instituído, é um dos guerreiros xavante, no entanto, em vez da borduna, empunha e manipula sua câmera.

As tomadas do conflito, consumadas com a câmera movente, remetem o espectador à intensidade do ocorrido e expõem a radicalidade da ação pretendida. Neste contexto, se existe alguma dose de aflição ela não é originária apenas do mecanismo, pois "a emoção da câmera não existe. Existe a intencionalidade do sujeito que a manipula" (Ibidem, p. 17). Cabe ressaltar que o gesto beligerante do documentarista revela não somente a perspectiva do seu registro, mas, acima de tudo, demonstra a sua atuação como sujeito político que compõe a luta por uma causa considerada justa pelo povo Xavante de Sangradouro.

\section{Vamos à luta! Parceria interétnica para ação política}

Gravado no contexto da luta pela homologação da TI Raposa Serra do Sol, no estado

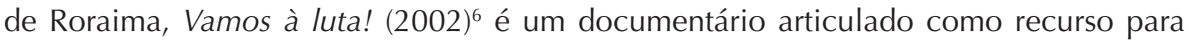
mobilizar a opinião pública em favor das reivindicações do povo Macuxi. De acordo com seu realizador, o objetivo da produção era "mostrar... ver se esse vídeo poderia dar voz para que saísse logo a homologação da terra dos Macuxi" (TSEREWAHú, 2018. Comunicação pessoal aos pesquisadores).

Os Macuxi organizavam um grande evento-manifesto e consideravam que o seu registro seria uma importante estratégia política, já que as imagens poderiam contribuir para o fortalecimento da demanda por território (note-se que, neste contexto, a TI Raposa Serra do Sol já estava demarcada, mas a luta pela homologação se estenderia até o ano de 2005). A obra mescla imagens captadas em três diferentes comunidades Macuxi, com um conjunto de captações sonoras do cineasta Divino Tserewahú.

O tom festivo com o qual se inicia a videorreportagem é interrompido por uma sequência que mostra a presença repentina de um jipe do Exército Brasileiro no pátio da comunidade. A tensão se estabelece exatamente pela incursão de um grupo militar ao insistir na autorização para um treinamento do Exército dentro do território. Nos primeiros planos da sequência, é possível observar que as imagens são captadas com o uso de uma teleobjetiva (lente tipo zoom), já que Divino parece estar abrigado estrategicamente para não ser percebido. Um corte seco para um plano geral aumenta a inquietação da cena, pois agora é possível acompanhar o cerco que alguns membros da comunidade fazem ao pequeno grupo de militares. A partir da negativa dessas pessoas (que acusam o Exército de adentrar reiteradamente o território sem a autorização da comunidade), o clima fica ainda mais apreensivo. Ao perceber que estão sendo filmados, os militares mudam de postura e passam a operar sob a égide de uma artificiosa diplomacia: "a ideia não é entrar na comunidade. A ideia não é nenhum tipo de agressão à comunidade. É só

6 O vídeo foi gravado no contexto de uma parceria entre o cineasta Divino Tserewahú e o projeto Vídeo nas Aldeias, coordenado pelo indigenista Vincent Carelli. 
para adestramento e intensificação do patrulhamento", dispara, quase sem jeito, o major responsável pela pequena patrulha.

De outra parte, a comunidade vale-se da presença da câmera para fortalecer uma performance de denúncia coletiva: "em vez de trabalhar pro seu filho, vem aqui só para perturbar minha família, minha comunidade. Aqui é a área Raposa Serra do Sol... Área única... é demarcada", esbraveja a mulher macuxi. Seguindo a mesma toada, uma outra indaga ao militar: "vocês querem fazer aquilo que aconteceu lá na Bahia? Com a gente, que vamos nos manifestar?". Certamente, este último questionamento ecoa, ainda no ano de 2002, a lembrança de um processo de violência sofrido por diferentes povos indígenas quando das manifestações contra a comemoração dos 500 anos de "descobrimento" ocorridas em abril do ano 2000.

Com efeito, a presença da câmera estimulou a ação de enfrentamento. É como se o dispositivo se colocasse ao mesmo tempo como uma espécie de escudo e caixa de ressonância. Escudo que, de alguma maneira, se converte em salvaguarda contra uma atitude mais agressiva do pequeno pelotão; caixa de ressonância como mecanismo possuidor da potência de reverberar a mensagem-denúncia para além do limite físico do território. Tal feito explica, em parte, o impulso repentino protagonizado pelas mulheres que disparavam, uma após a outra, seus brados de contestação. Este "efeito-câmera", pensado por Xavier (2014) e replicado por Laércio Rodrigues, "pressupõe a câmera como elemento que aciona performance, que intensifica ou arrefece condutas, que acolhe ou desmistifica desejos"7 (RODRIGUES, 2015, p. 142). Ademais, a sequência denota um estado de cumplicidade entre o antecampo, lugar de recuo onde Divino aloja sua câmera, e o campo, o domínio das imagens ardilosamente despidas para o espectador.

Depois de apresentar um conjunto de práticas culturais típicas do povo Macuxi, os planos seguintes denunciam as instalações militares que fazem divisa com a terra indígena. De um lado da rua, a imagem revela as humildes casas dos moradores, do outro, exibe as ostentosas instalações militares, alertando para o risco iminente do conflito. Outro conjunto de tomadas traz para o espectador a leitura visual que reforça o poderio do Exército de fronteira. O tanque, a cavalaria, os soldados armados e o helicóptero, fazendo voos rasantes sobre o telhado de palha das habitações tradicionais, convidam o espectador a refletir sobre o dispositivo de vigilância ao qual o povo Macuxi está constantemente exposto (Figura 3). Fica nítida a intenção figurativa da sequência de imagens que evidenciam a violência simbólica produzida pela movimentação orquestrada do corpo militar.

7 Para Xavier, a noção de "efeito-câmera" pode ser pensada sob o viés de "uma instância de teatralidade que acentua o gesto performativo dos que estão sob o olhar da câmera, como acontece com os entrevistados, cientes de que o registro terá dimensão pública" (2014). 


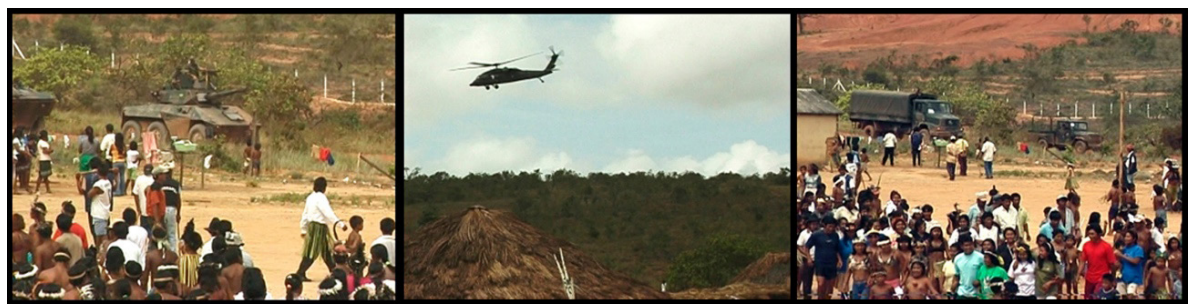

Fig. 3. Comunidade indígena em constante estado de vigilância - TI Raposa Serra do Sol. Fonte: Frames do filme Vamos à luta! (2002).

\section{O sujeito e a câmera}

Ramos (2012) nos alerta que a câmera, ao menos na perspectiva de sua função fundamental que é captar imagens, não existe sem a presença do sujeito. O equipamento, enquanto objeto, não é possuidor de vontade própria. Não obstante, para que a imagem aconteça é necessária a ação de um sujeito que não só a ative, como também direcione o seu olhar. Para o autor "importa realçar que há sempre um sujeito que acompanha o evoluir da câmera no mundo [...] A câmera e seu sujeito compõem, portanto, uma unidade indissociável" (Ibidem, p. 77).

Cogitamos que a dimensão inscrita nesta unidade (sujeito + câmera) é o que provoca o "efeito-câmera" descrito por Xavier (2014) e Rodrigues (2015). Trata-se de uma potência que se dará na materialidade da imagem por meio do encontro com seu espectador. Ou seja, num espaço que está no âmbito comunitário (no caso em que as exibições são feitas no próprio interior da comunidade) ou para além dele. Caberia a seguinte indagação: o que essas imagens podem provocar (em termos de sensibilidade, de afetos, de subjetividades e de ação política) no processo de fruição durante o contato com seu espectador? Talvez nas respostas a esta pergunta é que esteja alojada a potência da "imagem-câmera". É justamente desta junção, geradora de potência, que ganha corpo a noção de "sujeitoda-câmera" proposta por Ramos:

A câmera sem sujeito é uma coisa, um objeto inerte a mais no mundo. Quando incorpora aquele, ou aqueles, que vão detonar seu mecanismo, e intencionalmente inseri-la, estática ou movente, na circunstância que a circunda, ela passa a existir em razão de sua potencialidade de constituir imagens para um espectador futuro. Não se trata, na verdade, de uma câmera com sujeito (que a manipula), mas, especificamente, de um sujeito-da-câmera, que surge como tal, principalmente ao pensarmos na constituição da imagem como um todo: naquilo que aponta e se lança para o momento da fruição espectatorial, sendo determinado por ele na potencialidade que tem de existir ao receber seu olhar. (RAMOS, 2012, p. 77) 
Esta aposta está ancorada exatamente quando levamos em consideração quem é o sujeito-da-câmera. Isso faz toda a diferença nas opções que delineiam as narrativas aqui cotizadas. É preciso ter em vista que este sujeito está submerso em uma historicidade, em uma experiência de pertencimento que, tal como o seu grupo originário (ou dos seus parentes), traz em seu corpo e em sua subjetividade a carga histórica da experiência contida no horizonte colonial (CUSICANQUI, 2010).

Isso posto, é possível antever que o sujeito-da-câmera não é um qualquer. Ele é, ademais, a extensão de um processo intersubjetivo: em primeiro lugar, de seu povo e, em segundo, da categoria social que se convencionou denominar genericamente de "índio". Este sujeito "índio", que não por acaso, nas narrativas aqui reportadas, é também o sujeito-da-câmera, é detentor de um posicionamento político, portanto, provém de um lugar de fala que o legitima a estar nas circunstâncias da cena. Ademais, ele não se quer imparcial, ao contrário, seu gesto está contaminado pelos afetos e valores que estão em jogo - seu corpo empunhando a câmera compõe o conflito.

O arrefecimento da autoridade militar e sua pretensão para a diplomacia contrastam com o encorajamento dos personagens indígenas que passam a disparar denúncias, apostando na potência de reverberação da câmera. Quanto mais esta se insinuava para a situação, mais as indignações ganhavam amplitude. Para o grupo militar não restou outra saída: o recuo para sua zona de conforto.

Insistimos em retomar a distinção entre dois diferentes momentos de uma sequência já narrada de Vamos à luta! a fim de evidenciar, por definitivo, como a presença da câmera interfere no encaminhamento da situação filmada. A primeira tomada foi realizada com a câmera em recuo, posicionada de uma forma tal que os sujeitos presentes no enquadramento não tinham a consciência de que estavam sendo filmados. Note-se que, aqui, o antecampo não se faz presente na esfera circunstancial da cena; a teleobjetiva possibilita que ele esteja arredado tanto dos personagens quanto da situação filmada. Após um corte seco, o segundo conjunto de imagens é feito com a câmera presente na circunstância da tomada. No ponto inicial, a postura do agente militar estabelece um nível de correlação de forças com algumas pessoas da comunidade; no seguinte (com a câmera em presença), é possível constatar certo encolhimento da figura militar e um posicionamento mais diplomático. A adjacência do campo e do antecampo é revelada pelo fio de lealdade que liga um ao outro: o sujeito-da-câmera e as pessoas que "roubam" a cena pertencem a uma categoria social que engrossou o mesmo lado da trincheira em uma história de luta recente que ainda reverbera em seus corpos.

É factível apostar que a câmera em recuo e a câmera em presença delineiam relações diferenciadas que claramente podem ser percebidas na cena. Sobre a presença ou ausência do dispositivo, Ramos faz a seguinte observação: "a 'câmera oculta' deixa o mundo seguir sua sucessão própria, mantendo-se ausente do campo efetivo da ação onde se delineia, em processo, o 'bloco' da realidade que vem impressionar o suporte" 
(Ibid., p. 75). Na sequência, a circunstância da tomada se conforma não só com a presença do equipamento em si, mas também com o sujeito que a manipula. Com a mudança de postura dos personagens o que se percebe é o desencadeamento do efeito-câmera. Neste sentido, conforme destaca o autor, o resultado passa a ser "a imagem da interação de seres e coisa com a presença marcante da câmera" (idem, p. 75).

Por fim, é curioso pensar sobre qual seria o desfecho se o sujeito-da-câmera não fosse um indígena e, sobretudo, um parente de confiança. Fosse ele um branco, teriam os Macuxi o mesmo ímpeto para a autodefesa diante da câmera? Parece coerente admitir que, no momento da tomada pela câmera, emerge um processo intersubjetivo que favorece a confiança e dá força aos indígenas (tanto para aqueles que são filmados quanto para aquele que filma).

\section{Imagens e afetos, considerações finais}

Como proposto por Cezar Migliorin, o documentarista não instaura uma cena, ao contrário, insiste o autor: "o documentarista parte de uma cena que o antecede. Seu poder catalizador opera articulando cena sobre cena, dobrando a cena" (2014, p. 243). Diante dessa provocação, parece coerente pensar que, no caso de Vamos à luta! e de Prisão e libertação de jovem xavante, o cineasta foi convocado a estar diante da cena e, como consequência, fazer o seu registro. Ao vivenciar a emoção e o tormento de cada cena, seu registro se torna carregado de subjetividades e afetos (da experiência de viver a cena) ou "sob o risco do real", como já sugeriu Jean-Louis Comolli (2001).

Pensando por este prisma, esses filmes se constituem como dispositivos que amalgamam desejos coletivos. Por sua vez, tais desejos modulam o olhar do documentarista que aposta na imagem como instrumento de ação política. Além de representar uma perspectiva política, a imagem convida o espectador a participar do evento, a vivenciar (sob diferentes sensibilidades) as aflições do ocorrido. Ainda com Migliorin, é possível ponderar que "a imagem se torna decisiva para que possamos saber sobre o evento e participar do conhecimento que o documentarista se propõe a produzir sobre o que vê" (Ibid., p. 250).

No primeiro caso (Prisão e libertação de jovem xavante), a presença do documentarista empunhando sua câmera certamente teve influência para um desfecho menos trágico do ocorrido. A lente da câmera se pôs como testemunho da negociação entre as autoridades policiais e as lideranças xavante, incorrendo em um instrumento que, em certa medida, foi apaziguador do litígio que deu sentido ao filme. No segundo (Vamos à luta!), a convocação do cineasta para registrar as manifestações, envolta em um importante marco político, circunscreve a agência da imagem como força política. Ou seja: em ambos os casos, fica clara a consciência de que o registro em áudio e vídeo ampliaria o alcance político da manifestação/ato dando a este uma expressividade simbólica, permitindo que pudesse ecoar em diferentes lugares. A viagem do documentarista xavante até o território da etnia Macuxi, em Roraima, compõe o conjunto das estratégias articuladas para a defesa do território.

No gesto de intercalar as cenas, na justaposição das imagens com seu lugar de indivíduo 
etnicamente definido (portanto, legitimado dentro de um grupo étnico), surgem os filmes. A montagem modula os anseios do cineasta em diálogo com as expectativas do seu povo. Subsiste, em sua concretude, uma afetação coletiva revelada pela maneira singular como o mundo é posto no quadro fílmico. Não seria exagero intuir que este gesto perturba um regime de visibilidade que é componente da faceta simbólica de um quadro de violência responsável por instaurar uma representação tenebrosa que nega a dignidade dos povos indígenas.

Esse "enquadramento" é potente, pois revela a trajetória do próprio cineasta que, junto com seu povo, vivenciou e vive, ainda hoje, um lugar marginal na sociedade. Como nos ensina Migliorin, "o acontecimento que busca o documentarista não é o outro da imagem, mas, como um nó da madeira, é parte do fluxo das coisas, passa pelo interior dos indivíduos e pela constituição da imagem" (MIGLIORIN, 2014, p. 260).

Os registros são atravessados pela aflição do real concreto, conflitos com risco de morte para indígenas na luta pelos seus territórios e afirmação de modos de vida. A materialidade destes registros está modulada por ações depreendidas por quem está no quadro fílmico, mas também por quem está no seu reverso. Ou seja, no campo e no antecampo que dão o sentido mesmo da existência dos filmes. Não obstante, esta ponderação se vincula à proposição de Jean-Louis Comolli quanto ao gesto de produzir documentário:

Filmar os homens reais no mundo real representa estar tomado pela desordem dos modos de vida, pelo indizível das vicissitudes do mundo, aquilo que do real se obstina a enganar as pressões. Impossibilidade do roteiro. Necessidade do documentário. (COMOLLI, 2001, n.p.)

No registro imagético da fúria xavante em torno do resgate de um de seus integrantes, a desordem do cotidiano impregnou a imagem entregando ao espectador a convulsão do momento filmado. A desobediência estética da câmera nervosa é o espelho da aposta na insubmissão civil de seus personagens, para os quais as leis do branco parecem não fazer muito sentido. A ocupação da delegacia, o desbarate da viatura e o sequestro da autoridade policial instituem o clamor dos personagens por uma outra noção de justiça. Nesta altura, nem a câmera, nem tampouco o cinegrafista, podem dominar a cena. O que resta, para este último, é exercer a essência de sua função: captar a ação e fazer dela uma narrativa, um registro mediador do ocorrido com seu contexto. Ou seja: renderse à "necessidade do documentário".

Dolores Galindo é professora do Departamento de Psicologia e do Programa de Pós-Graduação em Estudos de Cultura Contemporânea da Universidade Federal de Mato Grosso.

dolorescristinagomesgalindo@gmail.com 
Gilson Costa é jornalista, cineasta, docente de Jornalismo e doutorando do Programa de Pós-Graduação em Estudos de Cultura Contemporânea da Universidade Federal de Mato Grosso.

gilsoncosta@gmail.com

\section{Referências}

ALVARENGA, C. M. C. Vídeo e experimentação social: um estudo sobre o vídeo comunitário contemporâneo no Brasil. 2004. Dissertação (mestrado) - Instituto de Artes. Campinas, Universidade Estadual de Campinas, SP.

BARROS, M.F. S. Caminhada, canto e conversação: mise-en-scène reversa em três filmes do Coletivo Mbyá-Guarani de Cinema. 2014. Tese (doutorado) - Faculdade de filosofia e Ciências Humanas, Universidade Federal de Minas Gerais, Belo Horizonte, MG.

BRASIL, A. Formas do antecampo: performatividade no documentário brasileiro contemporâneo. FAMECOS: mídia, cultura e tecnologia, 2013. Disponível em: <http://revistaseletronicas.pucrs.br/ ojs/index.php/revistafamecos/article/viewArticle/14512>. Acesso em: 7 maio 2019.

COMOLLI, J. Sob o risco do real. In: Catálogo do Forumdoc. Belo Horizonte, 2001.

CUSICANQUI, S. R. Oprimidos pero no vencidos: luchas del campesinado aymara y qhechwa 19001980. La Paz: Piedra Rota, 2010.

MIGLIORIN, C. Ensaio na revolução: o documentarista e o acontecimento. In: GONÇALVES, O. (Org). Narrativas sensoriais: ensaios sobre cinema e arte contemporânea. Rio de Janeiro: Editora Circuito, 2014.

RAMOS, F. P. A imagem-câmera. Campinas: Papirus, 2012.

RODRIGUES, L. R. A. Notas sobre o dispositivo no documentário contemporâneo. Galaxia, n. 30, p. 138-148, dez. 2015. Disponível em: <http://dx.doi.org/10.1590/1982-25542015220160>. Acesso em: 07 maio 2019.

XAVIER, I. A teatralidade como vetor do ensaio fílmico no documentário brasileiro contemporâneo. Aniki: Revista Portuguesa da Imagem em Movimento, América do Norte, 1 jan. 2014. Disponível em: <http:// aim.org.pt/ojs/index.php/revista/article/view/52/19>. Acesso em: 7 maio 2019.

Filmografia:

Prisão e libertação de Jovem Xavante. Dir.: Divino Tserewahú. Brasil, 2009, DVD, 17'.

Vamos à luta! Dir.: Divino Tserewahú. Vídeo nas Aldeias, Brasil, 2002, DVD, 18’ 